\title{
THE MONGOLIAN IDIOT
}

\section{A preliminary Note ON the SElla turcica Findings}

WALTER TIMME, M.D.

NEW YORK

In the past year it has been my great privilege to examine a number of Mongolian defectives at Waverley, Mass., at the invitation of Dr. Walter E. Fernald. The case reports, complete clinical data, biochemical findings and the result of treatment on an endocrinologic basis will be the substance of a later communication by Dr. Fernald and myself. I desire to make at this time a preliminary publication of the findings of the roentgenologic examination of many of the skulls for the reason that it may stimulate the making of such examinations in many centers with possible corroboration of my findings. Furthermore, if necropsy material is available, a special effort might be made, on the basis of the sellar changes shown in the radiographs, to determine the pathology of the pituitary body.

In twenty-three out of twenty-four nonselected cases of Mongolian idiocy, including six of my own, the radiograph of the skull showed a peculiar change from the normal in the anterior portion of the fossa pituitaria. This change consisted in an excavation under the anterior clinoid processes and presumably under the olivary process and optic groove, and the excavation communicated directly with the anterior portion of the fossa itself. There were varying degrees of this excavation, as seen in the accompanying illustrations. From our knowledge, more or less exact, of the influence of the anterior lobe of the pituitary on growth and genital development, this roentgen-ray finding is of considerable interest. Especially is this true when we remember that among the clinical signs of Mongolian idiots we invariably have the combination of subnormal and disproportionate body growth coupled with lack of genital development. Thus in boys, undescended testicles are quite frequent and in girls abnormalities of the genitals with tardy menstrual flow or even complete amenorrhea are the rule. The intimate relationship which in early life exists between the anterior hypophysial lobe and the pharyngeal glandular elements is also strikingly coincidental with the extreme pharyngeal mucous secretion seen in Mongolian idiots. Furthermore, with such an excavation, involving at times the optic groove, eye symptoms should be of frequent occurrence. These 
ocular manifestations have been the subject of much discussion among ophthalmologists and a rather complete résumé of their findings was published some years ago by Charles A. Oliver. ${ }^{1}$ Among the findings are:

"The optic discs in a number of cases are unequally grayed, especially in the deeper layers and to the temporal sides; the substance of the disc in the great majority of cases, especially where the retinal and choroidal disturbance was not pronounced, is apparently edematous; the retina surrounding the optic nerve head is edematous and swollen in many of the cases; examination for visual field disturbances could never be properly carried out through lack of cooperation."

Theoretically, therefore, disturbance of the anterior portion of the pituitary body might readily produce many of the symptoms shown clinically by Mongolian idiots. It is therefore suggested that every necropsy examination in cases of Mongolian idiocy should include a careful examination of the pituitary gland, notably in its anterior portion. Should such an examination eventuate in a corroboration of antemortem findings, perhaps a rational treatment might be forthcoming for these cases. Indeed, even on the theoretical basis of anterior lobe disturbance, the writer has inaugurated a therapy in several of his cases which has had some degree of success thus far. In one of his Mongolian idiots the testicles have descended since treatment was begun, and there seems to be a measure of mental improvement likewise. This treatment includes the hypodermatic injections of anterior lobe extract (antuitrin) combined with whole gland feeding and thyroid administration in small doses.

It is important to observe, nevertheless, that excavation under the anterior clinoids and optic groove is seen occasionally in persons who have not Mongolian characteristics, but who have isolated symptoms and signs due to anterior lobe disturbance, namely, growth and genital developmental abnormalities.

Speculation as to the character of the contents of this excavation would at the present be idle. Suffice it to say, however, that on theoretical grounds it should be tissue foreign to the normal anterior lobe type and possibly interfering with whatever of normal structure may remain in the region.

There is included in the series of photographs accompanying this communication one of a Chinese girl, 13 years of age, who is normal in all ways, in order that a comparison may be made of her sella turcica

1. Oliver, C. A.: Med. Rec., Oct. 3, 1891. 


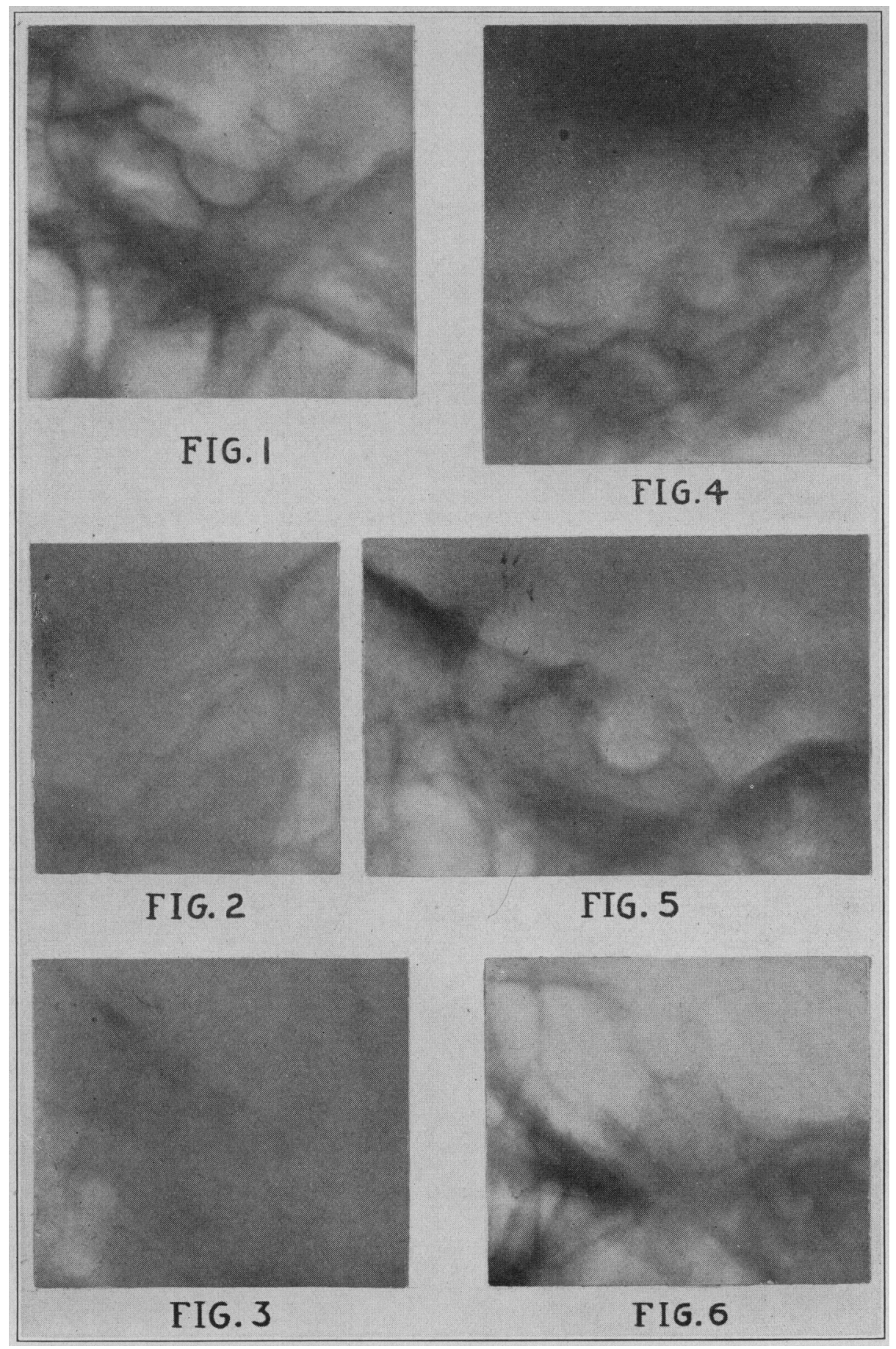

Fig. 1 (T. J., girl. Waverley).-The sella turcica is rather generally enlarged with a marked excavation anteriorly opening directly into the general pituitary fossa.

Fig. 2 (S. H., girl, author's patient).--Anterior excavation prominent and even somewhat larger than the pituitary fossa itself.

Fig. 3 (T. S., boy. Waverley).-Similar to Figure 2.

Fig. 4 (L. H., girl, author's patient).-Anterior excavation rather different from foregoing in that while it is fairly long, its width is less.

Fig. 5 (F. M., girl, Waverley).-Similar to Figure 4, with a narrow and rather short cavity anteriorly.

Fig. 6 (Chinese girls).-Normal sella turcica. Kindiess of Percy Ashley. 
with that of the Mongolian idiot. It will be seen that in her skull the pituitary fossa seems to be normal in all particulars, however different the other skull landmarks may appear to be.

From time to time observers have been adding additional findings in their reports on Mongolian idiocy, but these findings have been practically all in the symptomatologic domain. The present report of

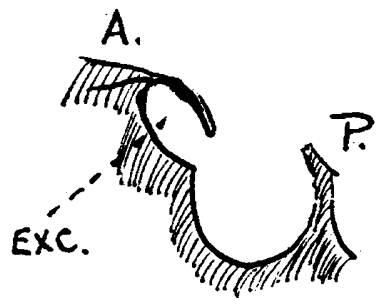

FIG.I

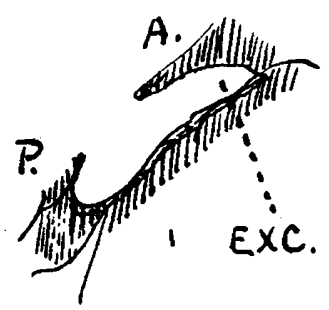

FIG.2

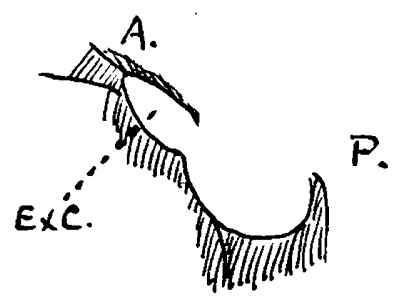

FI6.3

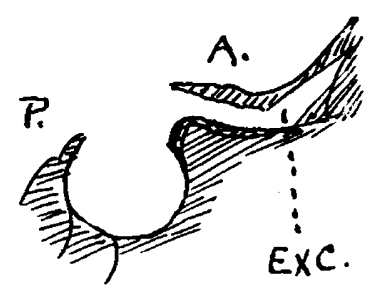

FIG. 4

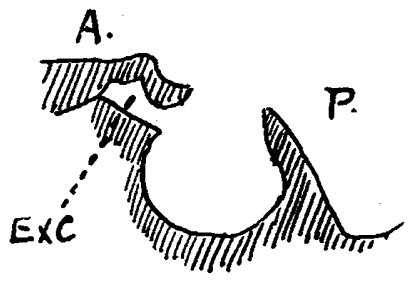

FI6.5

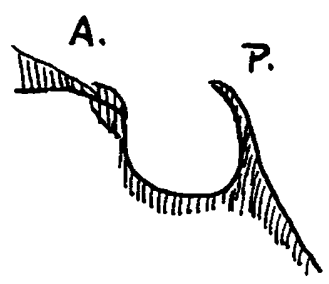

FI6.6

Fig. 7.-Diagrams illustrating sella photographs. A, anterior clinoid process, P, posterior clinoid process; Exc., excavation.

the sellar changes, if substantiated by the necropsy examination, is of quite a different nature, for it furnishes at once a basis for the structural changes of the Mongolian idiot and for the greater part of his symptomatology, and hence must be regarded as one of the fundamentals of the situation. Furthermore, it offers an angle of attack in therapy. 